\title{
Sistemas de custeio na administração pública municipal: uma aplicação da gestão de custos na Secretaria Municipal da Agricultura e Meio Ambiente de São João do Oeste - SC
}

Ari Söthe Mestrado em Ciências Contábeis pela Universidade Regional de Blumenau - FURB Rua Antonio Veiga, 104 (FURB/PPGCC). Blumenau/SC. CEP: 89012-900

E-mail: ari_sothe@yahoo.com.br Mestrado em Ciências Contábeis pela Universidade Regional de Blumenau - FURB Rua Antonio Veiga, 104 (FURB/PPGCC). Blumenau/SC. CEP: 89012-900 E-mail:smmarcelo@terra.com.br

Selma Hahn Reichert Faculdades de Itapiranga pela Faculdade de Itapiranga - FAI Rua Calos Kummer, 100. Itapiranga/SC. CEP: 89896-9000 E-mail:selmahahn@yahoo.com.br Jorge Eduardo Scarpin
Doutorado em Controladoria e Contabilidade pela Universidade Federal de São Paulo -
UFSP
Rua Antonio Veiga, 104 (FURB/PPGCC). Blumenau/SC. CEP: $89012-900$
E-mail: jorgescarpin@furb.br

\section{RESUMO}

A legislação da administração pública estabelece um conjunto de procedimentos que o gestor público municipal deverá adotar para garantir a eficiência na gestão dos recursos públicos. A realização de processos licitatórios nas aquisições, a prestação de contas da gestão fiscal e orçamentária, permitem a redução de custos em nível municipal. No aspecto contábil, ferramentas inovadoras como a elaboração do balanço social, publicação de relatórios simplificados e utilização do orçamento participativo, permitem aumentar os níveis de transparência. No entanto, uma ferramenta inovadora que poderá aperfeiçoar a utilização dos recursos e ampliar a visão dos resultados da gestão em todos os setores da administração municipal é a gestão de custos. O estudo tem como objetivo avaliar os custos da Secretaria Municipal de Agricultura e Meio Ambiente de São João do Oeste - SC, por meio da aplicação de um sistema de gestão de custos. Efetuou-se uma pesquisa descritiva, por meio do estudo de caso e com abordagem quantitativa, utilizando-se os documentos contábeis e relatórios de controle desta secretaria, com a aplicação da metodologia do custeio por absorção. Os resultados da pesquisa demonstram a viabilidade da implantação de um sistema de gestão com a utilização da metodologia do custeio por absorção. Os resultados encontrados servem 
Sistemas de custeio na administração pública municipal: uma aplicação da gestão de custos na Secretaria Municipal da Agricultura e Meio Ambiente de São João do Oeste - SC Ari Söthe, Marcelo Silva, Selma Hahn Reichert, Jorge Eduardo Scarpin

de apoio aos gestores desta secretaria e ampliam a qualidade na aplicação dos recursos públicos e sua prestação de contas para a sociedade.

Palavras-chave: Gestão de custos. Custeio por absorção. Secretaria Municipal.

Costing systems in municipal government: an application of cost management in the municipal secretary of agriculture and environment of São João do Oeste - SC

\section{ABSTRACT}

The legislation of the public administration establishes a group of procedures that the municipal public manager should adopt to guarantee the efficiency in the administration of the public resources. The accomplishment of bidding processes in the acquisitions, the accounts rendered of the fiscal and budget administration, allow the reduction of costs at municipal level. In the accounting aspect, innovative tools as the elaboration of the social swinging, publication of simplified reports and use of the participatory budgeting, allow to increase the transparency levels. However an innovative tool that can improve the use of the resources and to enlarge the vision of the results of the administration in all of the sections of the municipal administration is the management cost. The study has as objective evaluates the costs of a municipal secretary of agriculture and environment of a municipal district of small load through the application of a system of cost management was the analyzed object in the Municipal Secretary of Agriculture and Environment of São João do Oeste - SC. A descriptive research was done, through the case study and with quantitative approach, being used the accounting documents and reports of control of this section, with the application of the methodology of absorption costing. The results of the research demonstrate the viability of the implantation of an administration system with the use of the methodology of absorption costing. The found results serve as support to the managers of this secretary and enlarge the quality in the application of the public resources and their accountability rendered for the society.

Key Words: Cost management. Absorption Costing. Municipal Secretary.

\section{INTRODUÇÃO}

A preocupação com a correta aplicação dos recursos públicos tem levado os gestores públicos a buscar ferramentas para tentar mensurar os custos de maneira adequada. A fragilidade das informações apresentadas pelas demonstrações contábeis, não permitem avaliar de forma concreta os resultados dos projetos e atividades e a conseqüente eficiência na gestão dos recursos. Para suprir esta necessidade, a 
Sistemas de custeio na administração pública municipal: uma aplicação da gestão de custos na Secretaria Municipal da Agricultura e Meio Ambiente de São João do Oeste - SC Ari Söthe, Marcelo Silva, Selma Hahn Reichert, Jorge Eduardo Scarpin

contabilidade, por meio da aplicação das metodologias de custos, poderá auxiliar os gestores demonstrando os custos e benefícios de cada projeto e atividade desenvolvidos.

A falta da unanimidade na aplicação de uma metodologia específica na gestão dos custos do setor público proporcionou a realização de pesquisa contábil voltada à discussão de diferentes métodos de custos que se adaptem a cada órgão ou setor específico das entidades públicas.

Desta forma, um conjunto de trabalhos foi anteriormente desenvolvido sobre custos na área pública, objetivando a orientação aos gestores e profissionais da área contábil na implantação de um sistema de custos.

Slomski (2001) criou um modelo conceitual para a mensuração e demonstração do resultado econômico gerado pela prestação de serviços públicos, de modo a contribuir com as pesquisas em desenvolvimento neste campo.

Cruz e Platt Neto (2007) apresentaram de forma simplificada, direta e mais prática possível, a metodologia do custeamento $A B C$ adaptado à realidade de entidades públicas, mais particularmente de pequenos municípios. De maneira semelhante, Ribeiro e Camacho (2006), aplicaram o Custeio ABC para um Centro Municipal de Educação Infantil.

Um dos trabalhos mais recentes que incorpora a metodologia do custeio por absorção a órgãos públicos municipais foi desenvolvido por Raupp (2008), que teve como objetivo analisar a gestão de custos no Legislativo Municipal por meio do custeio por absorção.

Seguindo a linha exposta, o presente estudo tem como objetivo avaliar os custos de uma secretaria municipal da agricultura e meio ambiente de um município de pequeno porte por meio da aplicação de um sistema de gestão de custos. Para atingir o objetivo proposto, foi desenvolvido um estudo de caso na secretaria municipal da agricultura e meio ambiente de São João do Oeste - SC, representando uma das cinco secretarias que compõem a estrutura orçamentária do poder executivo deste município. Os dados utilizados referem-se ao exercício de 2007 e foram coletados junto à secretaria objeto de estudo e do departamento de contabilidade. 
Sistemas de custeio na administração pública municipal: uma aplicação da gestão de custos na Secretaria Municipal da Agricultura e Meio Ambiente de São João do Oeste - SC Ari Söthe, Marcelo Silva, Selma Hahn Reichert, Jorge Eduardo Scarpin

O estudo se justifica pela necessidade de exploração do tema e aplicação empírica nas entidades públicas, objetivando a identificação de metodologias de custos aplicáveis a todos os setores. Assim, o estudo individualizado da secretaria municipal da agricultura e meio ambiente ampliará os subsídios para justificar a importância da aplicação de determinada metodologia e a necessidade da gestão de custos em nível municipal.

O estudo também contribui para alcançar a eficiência nos gastos públicos municipais, demonstrando as atividades desenvolvidas e os custos incorridos para a obtenção dos produtos. Assim, permite aos gestores públicos municipais analisar os custos efetivos para compará-los com os custos incorridos nos demais municípios e criando alternativas como a terceirização de atividades.

A organização do estudo compõe-se de cinco seções, iniciando com essa introdução. Posteriormente apresenta-se a fundamentação teórica que sustenta o estudo, seguida dos aspectos metodológicos utilizados no seu desenvolvimento. Após são descritos, analisados e interpretados os dados coletados. Encerrando, apresentamse as conclusões do estudo e recomendações para futuras pesquisas inerentes ao tema abordado.

\section{FUNDAMENTAÇÃO TEÓRICA}

\subsection{A gestão de custos no setor público}

A obrigatoriedade da utilização de sistemas de custos nas entidades públicas foi instituída inicialmente pela Lei $n^{\circ} 4.320 / 1964$ em seu artigo 99; logo a seguir for reforçada pelo art. 79 do Decreto Lei $n^{\circ}$ 200/1967 e recentemente pela Lei Complementar n 101/2000 (Lei de Responsabilidade Fiscal - LRF), que estabelece a obrigatoriedade da implantação de sistemas de custos nos órgãos públicos, como destaca o seu parágrafo $3^{\circ}$ : "A Administração Pública manterá sistema de custos que permita a avaliação e o acompanhamento da gestão orçamentária, financeira e patrimonial".

A normatização recente introduzida pelo Conselho Federal de Contabilidade 
Sistemas de custeio na administração pública municipal: uma aplicação da gestão de custos na Secretaria Municipal da Agricultura e Meio Ambiente de São João do Oeste - SC Ari Söthe, Marcelo Silva, Selma Hahn Reichert, Jorge Eduardo Scarpin

(CFC), que busca a convergência da contabilidade pública as International Public Sector Accounting Standard (IPSAS), Padrões Internacionais de Contabilidade do Setor Público, estabelecem, entre outros, a implantação da contabilidade de custos no setor público. A Resolução CFC n 1.129/2008 estabelece os novos subsistemas de informações, destacando-se o subsistema de custos que servirá para registro, processamento e evidenciação dos custos dos bens e serviços, produzidos e ofertados à sociedade pela entidade pública.

Adicionalmente, a Resolução CFC no 1.133/2008, item 36, cria a Demonstração do Resultado Econômico que é assim compreendida:

A Demonstração do Resultado Econômico deve ser elaborada considerando sua interligação com o sistema de custos e apresentar na forma dedutiva, pelo menos, a seguinte estrutura:

(a) receita econômica dos serviços prestados e dos bens ou dos produtos fornecidos;

(b) custos e despesas identificados com a execução da ação pública; e

(c) resultado econômico apurado.

Portanto, fica evidente a obrigatoriedade da implantação da contabilidade de custos no setor público, cabendo aos municípios se adequarem a esta nova obrigação como fonte de informações para a tomada de decisão.

Para Slomski (2003), o serviço público é um conjunto de atividades colocadas à disposição da população, prestadas diretamente, permitidas ou concedidas pelo estado, visando proporcionar o maior grau possível de bem-estar social à coletividade. Por esta razão justifica-se a existência do estado como uma entidade prestadora de serviços e útil aos indivíduos que a compõem. Desta forma, a prestação de serviços do estado deve ser planejada dentro da economicidade e eficiência na aplicação dos recursos.

Reis, Ribeiro e Slomski (2005) destacam que os produtos que consomem custos nas entidades públicas não conseguem ser avaliados da mesma forma como nas empresas do setor privado, onde a diminuição da qualidade do produto representa rejeição e perda de produtos. Destacam que o setor público é compreendido como prestador de serviços de natureza complexa, basicamente formados por processos de 
Sistemas de custeio na administração pública municipal: uma aplicação da gestão de custos na Secretaria Municipal da Agricultura e Meio Ambiente de São João do Oeste - SC Ari Söthe, Marcelo Silva, Selma Hahn Reichert, Jorge Eduardo Scarpin

trabalho não percebidos por seus consumidores.

Para Cruz e Platt Neto (2007), na contabilidade pública o termo relacionado a custos que mais se assemelha com o setor privado é a despesa orçamentária, na qual estão incluídos: pessoal e encargos, juros, despesas correntes, investimentos, inversões financeiras e amortização de dívidas.

Silva (2007, p. 4) classifica a contabilidade de custos no setor público como pilar de apoio ao processo decisório, auxiliando os gestores em:

a) decidir entre produzir e prestar serviços ou terceirizar sua execução; b) calcular e justificar o valor das taxas e preços públicos a serem cobrados; c) facilitar a elaboração dos orçamentos; d) medir a eficiência, eficácia, economia, sub-atividades ou sobre-atividades; e) fundamentar o valor dos bens produzidos pelo órgão para uso próprio ou bens de uso comum do povo; f) apoiar decisões sobre continuar responsável pela produção de determinado bem, serviço ou atividade ou entregar a entidades externas; g) facilitar informação a entidades financiadoras de produtos, serviços ou atividades; h) comparar custos de produtos ou serviços similares entre diferentes órgãos do setor público; i) determinar o valor pelo qual deve ser registrado contabilmente um ativo que está sendo produzido pela própria administração.

Carvalho, Costa e Macedo (2007) destacam a implantação de um sistema de contabilidade de custos que terá por objetivos: a) justificar os preços cobrados pelo órgão público; b) mensurar a eficiência e economia nas atividades; c) apoiar as decisões em manter as atividades ou terceirizar; d) fornecer informações para financiadores; e) comparação de custos entre entidades diferentes; f) comparação de custos entre diferentes exercícios; g) comparar custos previstos e custos realizados.

Segundo Slomski (2003), a administração pública, como qualquer empresa privada, deve conhecer o custo daquilo que produz. Dessa forma, devem ser utilizados métodos de custeio capazes de viabilizar sua aplicação, com a finalidade de poderem tomar as melhores decisões entre as alternativas de produzir ou comprar produtos e serviços, de produzir ou privatizar serviços. 
Sistemas de custeio na administração pública municipal: uma aplicação da gestão de custos na Secretaria Municipal da Agricultura e Meio Ambiente de São João do Oeste - SC Ari Söthe, Marcelo Silva, Selma Hahn Reichert, Jorge Eduardo Scarpin

\subsubsection{Sistemas de custeio}

A implantação de um sistema de custos deve ser feita de maneira gradativa, levando em conta que a qualidade das informações geradas vai depender da qualidade do pessoal envolvido na alimentação e seu processamento (MARTINS, 2003). Complementa o autor, que a implantação de um sistema de custos deve ser feita de maneira progressiva e a melhoria da qualidade das informações será acompanhada gradualmente, levando em consideração a qualidade do pessoal envolvido no processamento e a necessidade da informação do usuário final. O sistema deverá contemplar e adequar-se às necessidades específicas de cada empresa.

O sistema de custo, baseado na apuração de custos reais, ou seja, os custos já incorridos são importantes para, no decorrer de um período, determinar o perfil da estrutura dos custos da empresa e fornecer dados relevantes na previsão de tendências futuras (IUDÍCIBUS, 1998).

Segundo Slomski (2003), na contabilidade das entidades públicas, por ser considerada orçamentária, todo consumo de recursos é registrado como despesas, classificadas em despesas correntes e despesas de capital. No entanto, quando as entidades quiserem efetuar o cálculo do custo, faz-se necessária a identificação do consumo de ativos para que se proceda à mensuração dos produtos ou serviços por ela produzidos. Uma vez consumidos e identificados os ativos, a entidade deverá decidir pelo sistema de custeio a ser utilizado para o cálculo do custo.

Para Slomski (2003), os sistemas que podem ser utilizados com maior sucesso na gestão governamental são: a) custeio por absorção; b) custeio direto ou variável; c) custeio padrão; e) custeio baseado em atividades.

Dentro da estrutura da organização, com a definição de processos, produtos ou serviços e direcionadores de custos, será possível estabelecer a melhor metodologia a ser aplicada a entidade.

\subsubsection{Custeio por absorção}

Para Martins (2003), a definição do sistema do custeio por absorção consiste na apropriação de todos os custos de produção aos bens elaborados, todos os gastos 
Sistemas de custeio na administração pública municipal: uma aplicação da gestão de custos na Secretaria Municipal da Agricultura e Meio Ambiente de São João do Oeste - SC Ari Söthe, Marcelo Silva, Selma Hahn Reichert, Jorge Eduardo Scarpin

relativos ao esforço de fabricação são distribuídos para todos os produtos ou serviços produzidos.

Garrison e Noreen (2001) destacam que o custeio por absorção atribui a cada unidade do produto, além dos custos variáveis uma parte do custo indireto de fabricação fixo.

O método de custeio por absorção, segundo Slomski (2003), é o que absorve todos os custos na produção de produtos ou serviços, sejam eles diretos ou indiretos, dentro de um determinado período de tempo. Os custos indiretos são alocados aos produtos ou serviços por rateio previamente definido.

Os custos diretos correspondem a todos os custos de produção que conseguem ser identificados aos produtos ou serviços, sem precisar passar por qualquer método de atribuição de custos (SLOMSKI, 2003). O autor complementa que os custos indiretos correspondem a aqueles que fazem parte do processo de produção, no entanto, não são identificáveis diretamente, necessitando de algum método para a atribuição destes custos aos produtos ou serviços.

No setor público, os custos alocados pelo sistema por absorção devem ser adaptados a realidade pública pelo fato da maioria se tratar de prestação de serviços. $O$ sistema de custeio se depara com algumas dificuldades quando se trata da separação dos custos comuns, que são aqueles que pertencem a mais de um serviço. Dessa forma, faz-se necessário a criação de um método para os custos indiretos, procurando que o mesmo cause a menor distorção possível no custo total (SLOMSKI ,2003).

Para uma distribuição mais racional dos custos indiretos, a departamentalização passa a fazer parte no sistema de custos por absorção. Com a departamentalização, os custos indiretos são rateados entre dois grupos, produção e os de serviços ou auxiliares. No departamento de produção os custos são apropriados diretamente ao produto e nos departamentos de serviços ou auxiliares esta apropriação direta aos produtos não é possível. Os departamentos de serviços ou auxiliares prestam serviços a outros e desta maneira os seus custos são transferidos para aqueles departamentos que são beneficiados. Posteriormente, os custos dos departamentos produtivos são distribuídos aos custos dos produtos (MARTINS, 2000). 
Sistemas de custeio na administração pública municipal: uma aplicação da gestão de custos na Secretaria Municipal da Agricultura e Meio Ambiente de São João do Oeste - SC Ari Söthe, Marcelo Silva, Selma Hahn Reichert, Jorge Eduardo Scarpin

Maher (2001) destaca como uma desvantagem do custeio por absorção o tratamento dos custos fixos como se fossem unitários, levando à avaliação incorreta de desempenho na tomada de decisões. No entanto, cita como uma das vantagens a sua aplicação com custos reduzidos, por não exigir a separação dos custos dos produtos em fixos e variáveis.

\subsubsection{Custeio direto ou variável}

Conforme Martins (2003), no sistema de custeio direto as despesas e os custos são classificados como fixos ou variáveis, alocando aos produtos os custos variáveis e os fixos separados e considerados como despesas do período

O método de custeio direto ou variável, para Slomski (2003), é o método que trata do consumo de ativos na elaboração de produtos e serviços em duas fases. $\mathrm{Na}$ primeira fase, são observados os custos variáveis ou diretos, que devem identificar os fatores que variam em função da produção e são diretamente identificáveis aos produtos ou serviços produzidos. Na segunda fase os custos fixos ou indiretos que independem de produção ou serviços são classificados como custos do período.

Maher (2001, p. 360) define o custeio variável como "sistema de contabilização de custos em que apenas os custos variáveis de produção são atribuídos aos produtos". Assim, por meio deste método os custos variáveis formam os custos dos produtos, pois os custos fixos em sua totalidade são considerados como despesas.

O custeio variável "atribui apenas os custos variáveis de manufatura em um nível de unidade ao produto; esses custos incluem os materiais diretos, a mão-de-obra direta e os CIF variáveis" (HANSEN; MOWEN, 2001, p. 668). Portanto, o custo dos estoques é representado somente pelos custos variáveis do produto, diminuindo consideravelmente o valor destes ativos, quando comparados com a aplicação das demais metodologias de custeio.

O custeio variável é "o método de custeio de estoque em que todos os custos de fabricação variáveis são considerados custos inventariáveis. Todos os custos de fabricação fixos são excluídos dos custos inventariáveis: eles são custos do período em que ocorreram" (HORNGREN; FOSTER; DATAR, 2000, p. 211). 
Sistemas de custeio na administração pública municipal: uma aplicação da gestão de custos na Secretaria Municipal da Agricultura e Meio Ambiente de São João do Oeste - SC Ari Söthe, Marcelo Silva, Selma Hahn Reichert, Jorge Eduardo Scarpin

Martins (2003) destaca que do ponto de vista decisorial, o custeio variável oferece informações fundamentais de forma muito mais rápida para a empresa. Apresenta maiores características informativas para a administração, por meio da medição do seu resultado, por abandonar os custos fixos e tratá-los como despesas.

\subsubsection{Custeio-padrão}

Segundo Slomski (2003), no método de custeio-padrão calcula-se o custo de uma unidade e atribui-se o custo para as demais. Depois de produzido ou realizado o serviço, apura-se o real incorrido para dessa forma apurar eventuais diferenças de preço, volume e tempo, etc.

Comenta ainda o autor, que o objetivo básico do cálculo do custo-padrão é o de se conhecer o custo daquilo que se pretende produzir para depois confrontar com o custo real. $\mathrm{Na}$ administração pública, ele pode ser mais bem utilizado na elaboração dos orçamentos anuais para a definição do montante dos recursos que cada atividade ou projeto necessitará para sua realização. Depois de executado, permite a comparação com os resultados alcançados (SLOMSKI, 2003).

\subsubsection{Custeio baseado em atividades (ABC)}

Garrison e Noreen (2001, p. 223) classificam o custeio ABC como "um método de custeio projetado para municiar os gerentes com informações de custo, para decisões estratégicas ou de outra natureza, que potencialmente afetem a capacidade e, por conseguinte, os custos "fixos. Da mesma forma, Martins (2003, p. 87) complementa que o custeio baseado em atividades "não se limita ao custeio de produtos. Ele é, acima de tudo, uma poderosa ferramenta a ser utilizada na gestão de custos".

Para Maher (2001), o custeio ABC consiste em atribuir custos aos produtos com base em todas as atividades necessárias para fabricação dos mesmos como, por exemplo, testes de qualidade; reparo de máquinas; engenharia de produtos e distribuição aos clientes. É também considerado por Martins (2003), o sistema que trabalha a idéia da diminuição das distorções provocadas pelo rateio arbitrário dos custos indiretos. 
Sistemas de custeio na administração pública municipal: uma aplicação da gestão de custos na Secretaria Municipal da Agricultura e Meio Ambiente de São João do Oeste - SC Ari Söthe, Marcelo Silva, Selma Hahn Reichert, Jorge Eduardo Scarpin

Segundo Slomski (2003), o método ABC preconiza que não são os produtos ou serviços que consomem recursos, mas sim as atividades, ou seja, as ações produzidas para sua produção que consomem os recursos disponibilizados à entidade pública.

Silva (2007) destaca como requisitos para a construção de um sistema de custos o completo entendimento: a) da estrutura organizacional da instituição; b) do procedimento ou processos de manufatura; c) do tipo de informação de custo desejada e exigida pela administração.

Slomski (2003) enfatiza que o sistema de custeio baseado em atividades para a administração pública é a metodologia mais adequada, pois permite trabalhar com diversidade de produtos e a que mais se adapta à tomada de decisões.

No setor público, a dificuldade em identificar a metodologia de custos mais adequada sempre esteve presente. O estudo de Villela (apud SILVA, 2007) destaca as metodologias de custeio que podem ter aplicação no setor público, conforme apresentado no Quadro 1. 
Sistemas de custeio na administração pública municipal: uma aplicação da gestão de custos na Secretaria Municipal da Agricultura e Meio Ambiente de São João do Oeste - SC Ari Söthe, Marcelo Silva, Selma Hahn Reichert, Jorge Eduardo Scarpin

\begin{tabular}{|c|c|c|c|}
\hline $\begin{array}{l}\text { Método de } \\
\text { Custeio }\end{array}$ & Conceito básico (Resumo) & $\begin{array}{l}\text { Aplicável } \\
\text { ao } \\
\text { serviço } \\
\text { público }\end{array}$ & Por que \\
\hline $\begin{array}{l}\text { Contabilidade de } \\
\text { ganhos (Teoria } \\
\text { das Restrições) }\end{array}$ & $\begin{array}{l}\text { Teoria composta de um processo } \\
\text { de aprimoramento contínuo a ser } \\
\text { aplicado nos processos de } \\
\text { produção por meio de um } \\
\text { raciocínio que identifique e } \\
\text { busque sempre melhorar a } \\
\text { restrição do sistema. }\end{array}$ & Não & $\begin{array}{l}\text { Despreza os custos fixos; } \\
\text { Atem-se apenas à matéria-prima } \\
\text { Tem como foco os ganhos que } \\
\text { na administração pública, em } \\
\text { certas circunstâncias, são } \\
\text { intangíveis. }\end{array}$ \\
\hline $\begin{array}{l}\text { Custeio Direto ou } \\
\text { Variável }\end{array}$ & $\begin{array}{l}\text { É o que somente aloca os custos } \\
\text { variáveis, ficando os fixos } \\
\text { separados e considerados como } \\
\text { despesas do período. }\end{array}$ & Não & $\begin{array}{l}\text { Não leva em consideração os } \\
\text { custos fixos como custos da } \\
\text { atividade produtiva e sim do } \\
\text { período considerado. } \\
\text { Tem como foco o cálculo da } \\
\text { margem de contribuição. }\end{array}$ \\
\hline $\begin{array}{l}\text { Custeio por } \\
\text { absorção }\end{array}$ & $\begin{array}{l}\text { Apropriação de todos os custos } \\
\text { de produção aos bens e serviços } \\
\text { produzidos. }\end{array}$ & Sim & $\begin{array}{l}\text { Tem aplicação gerencial e, } \\
\text { exceto com relação a itens não } \\
\text { monetários como depreciação, } \\
\text { amortização e exaustão, pode ser } \\
\text { compatibilizado com o orçamento } \\
\text { anual, embora exista dificuldade } \\
\text { no rateio dos custos indiretos. }\end{array}$ \\
\hline $\begin{array}{l}\text { Custeio baseado } \\
\text { em atividades }\end{array}$ & $\begin{array}{c}\text { É o método que primeiro rastreia } \\
\text { os custos para as atividades e, } \\
\text { em seguida, para os produtos e } \\
\text { outros objetos de custo. }\end{array}$ & Sim & $\begin{array}{l}\text { Não segrega custos e despesas, } \\
\text { mas separa atividades que } \\
\text { agregam valor das que não } \\
\text { adicionam valor aos produtos ou } \\
\text { serviços. }\end{array}$ \\
\hline $\begin{array}{l}\text { Custeio pleno } \\
\text { (RKW) }\end{array}$ & $\begin{array}{c}\text { Trata do custeio pleno com a } \\
\text { apropriação de todos os custos } \\
\text { de produção e de todas as outras } \\
\text { despesas. }\end{array}$ & Sim & $\begin{array}{l}\text { Na administração pública não } \\
\text { existe, em princípio, a } \\
\text { segregação de ambiente de } \\
\text { produção e de distribuição e } \\
\text { vendas. } \\
\text { Sendo atividade sem fins } \\
\text { lucrativos, não tem muito sentido } \\
\text { segregar custos de despesas. }\end{array}$ \\
\hline
\end{tabular}

Quadro 1: Aplicabilidade dos métodos de custeio no setor público

Fonte: Villela apud Silva (2007, p. 9).

O Quadro 1 destaca os métodos de custeio por absorção, baseado em atividades e custeio pleno, como aplicáveis nas entidades públicas. O custeio por absorção é viável pela sua compatibilidade com o orçamento, no entanto, apresenta como limitação as dificuldades na definição dos critérios de rateios para a distribuição dos custos indiretos. O custeio baseado em atividades também é indicado pelo fato de primeiramente rastrear os custos por atividade e depois ratear aos produtos. O custeio pleno por apropriar todos os custos e despesas ao produto poderá ser aplicado, pois 
Sistemas de custeio na administração pública municipal: uma aplicação da gestão de custos na Secretaria Municipal da Agricultura e Meio Ambiente de São João do Oeste - SC Ari Söthe, Marcelo Silva, Selma Hahn Reichert, Jorge Eduardo Scarpin

inexiste a separação de setor produtivo dos demais setores nas entidades públicas.

\section{PROCEDIMENTOS METODOLÓGICOS}

O presente estudo é classificado quanto aos objetivos como descritivo. Para Raupp e Beuren (2004, p. 81), "a pesquisa descritiva configura-se como um estudo intermediário entre a pesquisa exploratória e a explicativa. "

Quanto aos procedimentos da pesquisa, é caracterizado como um estudo de caso, sendo utilizados dados primários. Gil (1999, p. 73) descreve que "o estudo de caso é caracterizado pelo profundo e exaustivo exame de um ou de poucos objetos, de maneira a permitir conhecimentos amplos e detalhados do mesmo, tarefa praticamente impossível mediante os outros tipos de delineamento considerados". Os dados primários foram coletados junto à contabilidade e secretaria municipal da agricultura e meio ambiente referente ao exercício de 2007, sendo submetidos a um estudo aprofundado para a definição da metodologia de custos adequada para esta secretaria.

O estudo é classificado quanto à abordagem como quantitativo, pois a entidade analisada não possuía estrutura de apuração e gestão de custos. O estudo se propõe a apresentar uma estrutura de gestão de custos com análise dos resultados por meio da aplicação da metodologia do custeio por absorção.

A definição da secretaria municipal da agricultura e meio ambiente de São João do Oeste - SC como objeto de estudo, ocorreu em função da acessibilidade e conveniência na obtenção dos dados. Outro aspecto importante para a definição da secretaria como objeto de estudo, foi à representatividade do setor agropecuário no movimento econômico do município, conforme apresentado na Tabela 1.

Tabela 1: Movimento Econômico de São João do Oeste, SC - 2007

\begin{tabular}{|c|c|c|}
\hline Atividade & Valor (R\$) & $\%$ \\
\hline Agricultura e Pecuária & $93.035 .428,00$ & 83,13 \\
\hline Indústria, Comércio e Serviços & $18.874 .333,00$ & 16,87 \\
\hline TOTAL & $\mathbf{1 1 1 . 9 0 9 . 7 6 2 , 0 0}$ & $\mathbf{1 0 0}$ \\
\hline
\end{tabular}

Fonte: Unidade Conveniada da Fazenda Estadual de São João do Oeste 
Sistemas de custeio na administração pública municipal: uma aplicação da gestão de custos na Secretaria Municipal da Agricultura e Meio Ambiente de São João do Oeste - SC Ari Söthe, Marcelo Silva, Selma Hahn Reichert, Jorge Eduardo Scarpin

O município de São João do Oeste - SC foi criado pela Lei Estadual número 8.475, de 12 de dezembro de 1991 e instalado no dia $1^{\circ}$ de janeiro de 1993, está localizado no Extremo Oeste do Estado de Santa Catarina, e é considerado um município de pequeno porte em função da sua população que é de 6.020 habitantes, seu Produto Interno Bruto é de $\mathrm{R} \$$ 67.314.000 (IBGE, 2007).

A fase inicial da pesquisa foi constituída do estudo das diferentes metodologias de custeio e a escolha do custeio por absorção pela sua viabilidade e simplicidade na implantação.

Foram excluídos do valor total das despesas desta secretaria, alguns itens como, valores pagos em bônus, organização de exposições e feiras livres, incentivos financeiros concedidos, convênios e serviços prestados pelos departamentos auxiliares a estes programas e atividades, por representarem simplesmente repasses de recursos e incentivos concedidos e não produtos efetivamente elaborados pela secretaria.

Os custos diretos foram alocados diretamente aos departamentos produtivos e aos produtos. Para a atribuição dos custos indiretos foi utilizada a departamentalização, alocando-se inicialmente estes custos aos departamentos auxiliares, em um segundo momento o rateio dos custos destes para os departamentos produtivos e finalmente para os produtos.

Assim, a estrutura é constituída por sete departamentos produtivos e dois auxiliares. O departamento de inseminação elabora oito produtos diferentes, representados pelos diferentes tipos de sêmen bovino fornecidos aos produtores rurais. Cada um dos demais departamentos elabora somente um tipo de produto.

O orçamento da secretaria municipal da agricultura e meio ambiente é uma unidade orçamentária integrante do orçamento geral do município, a sua execução ocorre de forma centralizada no órgão correspondente a Prefeitura Municipal de São João do Oeste - SC.

As atividades desenvolvidas no setor estão relacionadas com o homem do campo, desempenhando atividades de incentivo e apoio à agricultura, bovinocultura, suinocultura, avicultura, apicultura, piscicultura, meio ambiente, entre outras atividades. A secretaria possui como objetivo principal a melhoria da qualidade de vida dos 
Sistemas de custeio na administração pública municipal: uma aplicação da gestão de custos na Secretaria Municipal da Agricultura e Meio Ambiente de São João do Oeste - SC Ari Söthe, Marcelo Silva, Selma Hahn Reichert, Jorge Eduardo Scarpin

moradores do município e atender o que estabelecem os artigos 133 e 168 da Lei $n^{\circ}$ 539/2000 (Lei Orgânica do Município de São João do Oeste - SC).

O artigo 133 da lei orgânica define as funções do município em relação ao meio ambiente. "Art. 133. O Município deverá atuar no sentido de assegurar a todos os cidadãos o direito ao meio ambiente ecologicamente saudável e equilibrado, bem de uso comum do povo e essencial à qualidade de vida".

Da mesma forma, o artigo 168, estabelece as atribuições do município em relação às políticas de desenvolvimento agrícola.

Art. 168. O Município terá uma política agrícola voltada para os seguintes objetivos:

I. o desenvolvimento da propriedade em todas as suas potencialidades levada em conta a proteção do meio ambiente;

II. a execução do programa de recuperação e conservação do solo, reflorestamento (dando preferência a essências nativas), irrigação, de aproveitamento de recursos hídricos e de outros recursos naturais;

III. a diversificação e rotação de culturas;

IV. o fomento da produção agropecuária;

V. o incentivo à agroindústria, regulamentado na forma da lei;

VI. o incentivo ao cooperativismo, ao sindicalismo e ao associativismo, regulamentado na forma da lei;

VII. o incremento a novas técnicas a todas as atividades agrícolas, beneficiando ao acesso àqueles que se dedicam a esta atividade.

Assim, o presente estudo limitou-se a identificar as atividades efetivamente desenvolvidas pela secretaria objeto de estudo e mensurar seus custos, por meio da aplicação do custeio por absorção, não cabendo nesta pesquisa a comparação dos custos com possíveis resultados apresentados por diferentes metodologias ou encontrados em outras entidades públicas.

\section{ANÁLISE E INTERPRETAÇÃO DOS DADOS}

São apresentados nesta seção, os dados coletados da secretaria objeto de 
Sistemas de custeio na administração pública municipal: uma aplicação da gestão de custos na Secretaria Municipal da Agricultura e Meio Ambiente de São João do Oeste - SC Ari Söthe, Marcelo Silva, Selma Hahn Reichert, Jorge Eduardo Scarpin

estudo, iniciando com o orçamento da secretaria, tendo sido eliminados os valores não utilizados na análise, separando custos das despesas e custos diretos de indiretos. Posteriormente, são apresentados os setores produtivos e auxiliares. Encerrando a seção são destacados os custos de cada um dos produtos elaborados.

Os dados inicialmente coletados correspondem ao orçamento da Secretaria Municipal da Agricultura e Meio Ambiente e a sua execução. Na Tabela 2 são apresentados os programas que constituem o orçamento e a sua execução no exercício de 2007.

Tabela 2: Despesa orçada e executada da secretaria municipal da agricultura e meio ambiente - 2007

\begin{tabular}{|c|c|}
\hline Programa & Valor (R\$) \\
\hline Preservação e Conservação Ambiental & $172.500,00$ \\
\hline Promoção da Produção Vegetal & $60.000,00$ \\
\hline Programa & Valor (R\$) \\
\hline Promoção da Produção Animal & $21.000,00$ \\
\hline Extensão Rural & $821.500,00$ \\
\hline Total Orçado & $1.075 .000,00$ \\
\hline Despesa Executada & $1.006 .690,08$ \\
\hline Economia Orçamentária & $68.309,92$ \\
\hline
\end{tabular}

Fonte: Dados da Pesquisa

Por meio da Tabela 2 percebe-se que ocorreu uma economia orçamentária correspondente a $\mathrm{R} \$ 68.309,92$. A economia orçamentária ocorre no final do exercício, quando existe saldo de uma dotação orçamentária, conforme destacado no XI da Lei 4320/64.

Para iniciar a atribuição dos custos a cada departamento, foi necessário identificar os valores gastos em outros programas que não envolvem a elaboração dos produtos da secretaria e correspondentes a programas de incentivo e assistência. Em seguida, foram identificados outros custos incorridos e que não integram o orçamento da secretaria. Tendo estes dados selecionados, foi possível separar os custos em diretos e indiretos como preconiza a metodologia do custeio por absorção.

$\mathrm{Na}$ tabela 3 é apresentada a separação dos custos diretos e custos indiretos, sendo destacado o valor das despesas com outros programas que não integrarão 0 cálculo dos custos de cada produto. 
Sistemas de custeio na administração pública municipal: uma aplicação da gestão de custos na Secretaria Municipal da Agricultura e Meio Ambiente de São João do Oeste - SC Ari Söthe, Marcelo Silva, Selma Hahn Reichert, Jorge Eduardo Scarpin

Tabela 3: Custos e despesas incorridas no período

\begin{tabular}{|c|c|}
\hline Custos e Despesas & Valor (R\$) \\
\hline Custos Diretos & $374.462,66$ \\
\hline Custos Indiretos & $61.503,91$ \\
\hline Despesas com Outros Programas & $607.294,46$ \\
\hline Total & $1.043 .261,03$ \\
\hline
\end{tabular}

Fonte: Dados da Pesquisa

Destaca-se na Tabela 3 o valor das despesas com outros programas que não integrarão o cálculo dos custos dos produtos e que correspondem a $R \$ 607.294,46$. Os custos diretos e indiretos correspondem ao valor total de $\mathrm{R} \$ 435.966,57$. Este valor será atribuído inicialmente aos departamentos e posteriormente aos produtos.

A diferença entre o valor da despesa executada $(R \$ 1.006 .690,08)$ e o total dos custos e despesas ( $R \$ 1.043 .261,03)$ correspondente ao valor de $R \$ 36.570,95$, representa os custos com energia elétrica, aluguel e depreciação que não fazem parte no orçamento da secretaria. A energia elétrica e aluguel são pagos e contabilizados de forma centralizada na secretaria da administração. A depreciação não corresponde a um desembolso efetivo, desta forma, não integra o orçamento da secretaria. No entanto, estes três elementos de custo devem ser incorporados aos custos dos produtos da secretaria municipal da agricultura e meio ambiente, independentemente da forma de registro contábil e pagamento.

$\mathrm{Na}$ Tabela 4 são demonstrados todos os custos diretos incorridos nos departamentos produtivos do período analisado. 
Sistemas de custeio na administração pública municipal: uma aplicação da gestão de custos na Secretaria Municipal da Agricultura e Meio Ambiente de São João do Oeste - SC Ari Söthe, Marcelo Silva, Selma Hahn Reichert, Jorge Eduardo Scarpin

Tabela 4: Custos diretos do período

\begin{tabular}{|c|c|c|c|c|c|c|c|c|}
\hline & \multicolumn{7}{|c|}{ DEPARTAMENTOS PRODUTIVOS } \\
\hline $\begin{array}{c}\text { CUSTOS } \\
\text { DIRETOS }\end{array}$ & Viveiro & Exatoria & $\begin{array}{c}\text { Horta } \\
\text { Familiar }\end{array}$ & Inseminação & Inspeção & Fontes & Veterinário & Total \\
\hline $\begin{array}{c}\text { Materiais } \\
\text { Diretos }\end{array}$ & $15.418,40$ & $4.524,82$ & $26.245,50$ & $146.133,35$ & 49,75 & $3.672,50$ & 831,38 & $196.875,70$ \\
\hline $\begin{array}{c}\text { CUSTOS } \\
\text { DIRETOS }\end{array}$ & Viveiro & Exatoria & $\begin{array}{c}\text { Horta } \\
\text { Familiar }\end{array}$ & Inseminação & Inspeção & Fontes & Veterinário & Total \\
\hline $\begin{array}{c}\text { Mão-de- } \\
\text { obra } \\
\text { Direta }\end{array}$ & $30.831,90$ & $21.807,85$ & - & - & $38.105,30$ & $1.240,20$ & $51.908,22$ & $143.893,47$ \\
\hline $\begin{array}{c}\text { Outros } \\
\text { Custos } \\
\text { Diretos }\end{array}$ & $2.631,35$ & $1.140,94$ & - & - & $9.334,15$ & $2.560,80$ & $18.026,25$ & $33.693,49$ \\
\hline Total & $48.881,65$ & $27.473,61$ & $26.245,50$ & $146.133,35$ & $47.489,20$ & $7.473,50$ & $70.765,85$ & $374.462,66$ \\
\hline
\end{tabular}

Fonte: Dados da Pesquisa

Os custos diretos incorridos na secretaria foram atribuídos diretamente aos departamentos produtivos, porque não necessitam passar por nenhum critério de rateio e estão diretamente ligados aos produtos elaborados. Conforme destacado por Slomski (2003), é importante para a contabilidade de custos a classificação dos custos, que podem ser diretos ou indiretos. Os custos diretos e indiretos estão vinculados à facilidade ou dificuldade de alocação dos insumos consumidos.

Por meio da tabela 5 são evidenciados todos os custos indiretos dos departamentos produtivos e auxiliares da secretaria. Os departamentos auxiliares identificados são o departamento técnico e administrativo que não atuam diretamente na elaboração dos produtos, no entanto, auxiliam os departamentos produtivos. 
Sistemas de custeio na administração pública municipal: uma aplicação da gestão de custos na Secretaria Municipal da Agricultura e Meio Ambiente de São João do Oeste - SC Ari Söthe, Marcelo Silva, Selma Hahn Reichert, Jorge Eduardo Scarpin

Tabela 5: Custos indiretos do período

\begin{tabular}{|c|c|c|c|c|c|c|c|c|c|}
\hline \multirow[b]{2}{*}{$\begin{array}{l}\text { CUSTOS } \\
\text { INDIRETOS }\end{array}$} & \multicolumn{6}{|c|}{$\begin{array}{l}\text { DEPARTAMENTOS } \\
\text { PRODUTIVOS }\end{array}$} & \multicolumn{2}{|c|}{$\begin{array}{c}\text { DEPARTAMENTOS } \\
\text { AUXLIARES }\end{array}$} & \multirow[b]{2}{*}{ Total } \\
\hline & Viveiro & Exatoria & $\begin{array}{c}\text { Horta } \\
\text { Familiar }\end{array}$ & Inseminação & Inspeção & Veterinário & Técnico & Administrativo & \\
\hline Energia & - & 333,47 & - & - & 333,47 & 333,47 & 365,45 & 233,43 & $1.599,29$ \\
\hline Aluguel & - & 312,09 & - & 307,72 & 185,18 & 185,18 & 387,04 & 247,22 & $1.624,43$ \\
\hline $\begin{array}{l}\text { Salários e } \\
\text { Encargos }\end{array}$ & - & - & - & - & - & - & $24.375,70$ & $15.569,96$ & $39.945,66$ \\
\hline Depreciação & - & - & - & - & - & - & $3.144,94$ & $2.008,83$ & $5.153,77$ \\
\hline Combustivel & - & - & - & - & - & - & $3.293,32$ & $2.103,61$ & $5.396,93$ \\
\hline $\begin{array}{c}\text { Material de } \\
\text { Consumo }\end{array}$ & - & - & - & - & - & - & $1.020,54$ & 651,87 & $1.672,41$ \\
\hline Telefone & - & - & - & - & - & - & 621,71 & 397,12 & $1.018,83$ \\
\hline Taxas & - & - & - & - & - & - & - & - & - \\
\hline $\begin{array}{c}\text { Manutenção } \\
\text { Equipamentos }\end{array}$ & - & - & - & - & - & - & 562,19 & 359,10 & 921,29 \\
\hline $\begin{array}{l}\text { Manutenção } \\
\text { Veiculo }\end{array}$ & - & - & - & - & - & - & $1.204,44$ & 769,34 & $1.973,78$ \\
\hline Diárias & - & - & - & - & - & - & $1.340,97$ & 856,55 & $2.197,52$ \\
\hline Total & - & 645,56 & - & 307,72 & 518,65 & 518,65 & $36.316,31$ & $23.197,02$ & $61.503,91$ \\
\hline
\end{tabular}

Fonte: Dados da Pesquisa

O custo indireto de energia foi rateado pelo número de computadores e periféricos utilizados em cada departamento. Para o rateio do aluguel foi utilizado como critério à área ocupada por cada departamento do imóvel onde se situa a Prefeitura Municipal de São João do Oeste - SC.

Os departamentos auxiliares, constituídos pelo departamento técnico e administrativo, possuem somente custos indiretos e seus valores serão rateados aos departamentos produtivos, conforme demonstrado na Tabela 6 . 
Sistemas de custeio na administração pública municipal: uma aplicação da gestão de custos na Secretaria Municipal da Agricultura e Meio Ambiente de São João do Oeste - SC Ari Söthe, Marcelo Silva, Selma Hahn Reichert, Jorge Eduardo Scarpin

Tabela 6: Custos indiretos dos departamentos produtivos

\begin{tabular}{|c|c|c|c|c|c|c|c|c|}
\hline $\begin{array}{c}\text { CUSTOS } \\
\text { INDIRETOS }\end{array}$ & Viveiro & Exatoria & $\begin{array}{c}\text { Horta } \\
\text { Familiar }\end{array}$ & Inseminação & Inspeção & Fontes & Veterinário & Total \\
\hline Energia & - & 333,47 & - & - & 333,47 & - & 333,47 & $1.000,41$ \\
\hline Aluguel & - & 312,09 & - & 307,72 & 185,18 & - & 185,18 & 990,17 \\
\hline $\begin{array}{c}\text { Departamento } \\
\text { Técnico }\end{array}$ & $24.210,87$ & - & - & - & - & $12.105,44$ & - & $36.316,31$ \\
\hline $\begin{array}{c}\text { Departamento } \\
\text { Administrativo }\end{array}$ & $3.313,86$ & $3.313,86$ & $3.313,86$ & $3.313,86$ & $3.313,86$ & $3.313,86$ & $3.313,86$ & $23.197,02$ \\
\hline Total & $27.524,73$ & $3.959,42$ & $3.313,86$ & $3.621,58$ & $3.832,51$ & $15.419,30$ & $3.832,51$ & $61.503,91$ \\
\hline
\end{tabular}

Fonte: Dados da Pesquisa

Os departamentos auxiliares possuem sua carga horária fixada na ficha de funções, estando definidas as horas que serão utilizadas por departamento produtivo. Assim, utilizaram-se como critério de rateio dos custos dos departamentos técnico e administrativo, as horas previamente definidas para utilização em cada departamento produtivo.

Os custos indiretos do departamento técnico foram rateados aos departamentos produtivos, correspondendo a $67 \%$ ao viveiro e $33 \%$ para as fontes. Os custos indiretos do departamento administrativo foram distribuídos igualmente a todos os departamentos produtivos, correspondendo a $14,28 \%$.

$\mathrm{Na}$ Tabela 7 são apresentados os custos dos produtos do departamento de inseminação, constituídos de 8 tipos de sêmen bovino, distribuídos gratuitamente aos agricultores do município como forma de incentivo a ampliação e melhoramento genético da atividade pecuária bovina. Os produtos são separados por raça, por possuírem valores do custo de aquisição diferenciados, permitindo desta forma uma análise do custo unitário apurado com o custo da aquisição. 
Sistemas de custeio na administração pública municipal: uma aplicação da gestão de custos na Secretaria Municipal da Agricultura e Meio Ambiente de São João do Oeste - SC Ari Söthe, Marcelo Silva, Selma Hahn Reichert, Jorge Eduardo Scarpin

Tabela 7: Custos dos produtos - Departamento de Inseminação

\begin{tabular}{|c|c|c|c|c|c|c|c|c|c|}
\hline \multirow[b]{3}{*}{ custos } & \multicolumn{8}{|c|}{ PRODUTOS } & \multirow[b]{3}{*}{ TOTAL } \\
\hline & \multicolumn{6}{|c|}{ SÊMEN - NORMAL } & \multicolumn{2}{|c|}{$\begin{array}{l}\text { SÊMEN - } \\
\text { MELHORAMENTO } \\
\text { GENÉTICO }\end{array}$} & \\
\hline & $\begin{array}{l}\text { Pardo } \\
\text { Suíço }\end{array}$ & Nelore & Jersey & Holandes & Gir & Angus & Jersey & Holandes & \\
\hline $\begin{array}{l}\text { CUSTOS } \\
\text { DIRETOS }\end{array}$ & $3.081,53$ & $3.489,16$ & $69.234,91$ & $46.919,91$ & $7.386,69$ & $2.224,11$ & $6.631,18$ & $7.165,86$ & $146.133,35$ \\
\hline Material & 402,53 & 703,71 & $9.569,31$ & $6.136,41$ & $1.567,29$ & 526,71 & 301,18 & 325,86 & $19.533,00$ \\
\hline Sêmen & $2.679,00$ & $2.785,45$ & $59.665,60$ & $40.783,50$ & $5.819,40$ & $1.697,40$ & $6.330,00$ & $6.840,00$ & $126.600,35$ \\
\hline $\begin{array}{c}\text { CUSTOS } \\
\text { INDIRETOS }\end{array}$ & 74,44 & 130,15 & $1.772,85$ & $1.140,94$ & 289,88 & 97,42 & 55,70 & 60,20 & 3.621 .58 \\
\hline Aluguel & 6,20 & 10,85 & 150,48 & 98,25 & 24,16 & 8,12 & 4,64 & 5,02 & 307,72 \\
\hline Administração & 68,24 & 119,30 & $1.622,37$ & $1.042,69$ & 265,72 & 89,30 & 51,06 & 55,18 & $3.313,86$ \\
\hline $\begin{array}{l}\text { CUSTO } \\
\text { TOTAL }\end{array}$ & $3.155,97$ & $3.619,31$ & $71.007,76$ & $48.060,85$ & $7.676,57$ & $2.321,53$ & $6.686,88$ & $7.226,06$ & $149.754,93$ \\
\hline $\begin{array}{c}\text { Quantidade } \\
\text { Aplicada }\end{array}$ & 282 & 493 & 6.704 & 4.293 & 1.098 & 369 & 211 & 228 & 13.678 \\
\hline $\begin{array}{l}\text { Custo Unitário } \\
\text { Apurado }\end{array}$ & 11,19 & 7,34 & 10,59 & 11,20 & 6,99 & 6,29 & 31,69 & 31,69 & \\
\hline CUSTOS & $\begin{array}{l}\text { Pardo } \\
\text { Suíço }\end{array}$ & Nelore & Jersey & Holandes & Gir & Angus & Jersey & Holandes & TOTAL \\
\hline $\begin{array}{l}\text { Custo de } \\
\text { Aquisição }\end{array}$ & 9,50 & 5,65 & 8,90 & 9,50 & 5,30 & 4,60 & 30,00 & 30,00 & \\
\hline
\end{tabular}

Fonte: Dados da Pesquisa

Por meio da tabela 7 é possível identificar a considerável diferença entre o custo unitário apurado e o custo de aquisição. Isto se explica pelo valor dos custos de material e custos indiretos alocados ao departamento de inseminação e posteriormente aos produtos. Percebe-se que este departamento e, conseqüentemente, os seus produtos não apresentam custos de mão-de-obra direta, pois os funcionários responsáveis pela inseminação são pagos por inseminação realizada, cabendo o pagamento aos produtores que se utilizam deste serviço.

$\mathrm{Na}$ tabela 8 são demonstrados os custos dos demais departamentos produtivos e a sua respectiva alocação a cada produto elaborado, cabendo a cada departamento os seguintes produtos: Viveiro (mudas produzidas), Exatoria (notas de produtor emitidas), Horta Familiar (mudas disponibilizadas), Inspeção (inspeções realizadas), Fontes 
Sistemas de custeio na administração pública municipal: uma aplicação da gestão de custos na Secretaria Municipal da Agricultura e Meio Ambiente de São João do Oeste - SC Ari Söthe, Marcelo Silva, Selma Hahn Reichert, Jorge Eduardo Scarpin

(fontes construídas) e Veterinário (atendimentos realizados).

Tabela 8: Custos dos demais produtos

\begin{tabular}{|c|c|c|c|c|c|c|c|}
\hline CUSTOS & $\begin{array}{c}\text { Mudas } \\
\text { Produzidas }\end{array}$ & $\begin{array}{c}\text { Notas de } \\
\text { Produtor } \\
\text { Emitidas }\end{array}$ & $\begin{array}{c}\text { Mudas } \\
\text { Disponibilizadas }\end{array}$ & $\begin{array}{c}\text { Inspeções } \\
\text { Realizadas }\end{array}$ & $\begin{array}{c}\text { Fontes } \\
\text { Construídas }\end{array}$ & $\begin{array}{c}\text { Atendimentos } \\
\text { Realizados }\end{array}$ & Total \\
\hline $\begin{array}{c}\text { Custo } \\
\text { Diretos }\end{array}$ & $48.881,65$ & $27.473,61$ & $26.245,50$ & $47.489,20$ & $7.473,50$ & $70.765,85$ & $228.329,31$ \\
\hline $\begin{array}{c}\text { Custos } \\
\text { Indiretos }\end{array}$ & $27.524,73$ & $3.959,42$ & $3.313,86$ & $3.832,51$ & $15.419,30$ & $3.832,51$ & $57.882,33$ \\
\hline Total & $76.406,38$ & $31.433,03$ & $29.559,36$ & $51.321,71$ & $22.892,80$ & $74.598,36$ & $286.211,64$ \\
\hline Quantidade & 335.400 & 22.330 & 258.714 & 5.972 & 71 & 2.330 & \\
\hline $\begin{array}{c}\text { Custo } \\
\text { Unitário }\end{array}$ & 0,23 & 1,41 & 0,11 & 8,59 & 322,43 & 32,02 & \\
\hline
\end{tabular}

Fonte: Dados da Pesquisa

Com base nos dados da tabela 8 foi possível identificar o custo unitário de cada produto dos demais departamentos produtivos da secretaria. Estes valores, assim como os obtidos na tabela 7, permitirão ao gestor inicialmente, reavaliar os valores cobrados por alguns dos produtos, a exemplo das mudas produzidas e disponibilizadas. Para os produtos fornecidos gratuitamente será possível avaliar o comportamento de seus custos ao longo do tempo, analisar a viabilização da terceirização de algumas atividades e comparar os custos destes produtos com os apurados em outras entidades públicas municipais com características semelhantes.

\section{CONCLUSÃO}

O estudo teve como objetivo avaliar os custos de uma secretaria municipal da agricultura e meio ambiente de um município de pequeno porte por meio da aplicação de um sistema de gestão de custos.

Visando atingir o objetivo proposto foi realizado um estudo descritivo, por meio de um estudo de caso realizado junto a Secretaria Municipal da Agricultura e Meio Ambiente de São João do Oeste - SC. Os dados foram coletados na secretaria analisada e contabilidade do município e aplicada à metodologia do custeio por 
Sistemas de custeio na administração pública municipal: uma aplicação da gestão de custos na Secretaria Municipal da Agricultura e Meio Ambiente de São João do Oeste - SC Ari Söthe, Marcelo Silva, Selma Hahn Reichert, Jorge Eduardo Scarpin

absorção.

Inicialmente os gastos da secretaria foram identificados em custos diretos, indiretos e despesas com outros programas. Os custos diretos foram alocados diretamente aos departamentos produtivos e posteriormente aos produtos. Os custos indiretos foram rateados aos departamentos produtivos e em seguida aos produtos.

Os resultados da aplicação da metodologia do custeio por absorção evidenciam que os custos apurados de alguns produtos são representativamente superiores ao custo de aquisição, como exemplo, o sêmen bovino fornecido aos agricultores. Os resultados apurados permitem aos gestores públicos identificar distorções na formação do preço de venda de alguns produtos e, principalmente, identificar estratégias para a sua avaliação e redução.

Desta forma, a implantação de um sistema de gestão de custos em nível municipal permite suprir a deficiência de informação gerencial apresentada pelas demonstrações contábeis tradicionais. Para o aperfeiçoamento do sistema de gestão de custos é recomendada a utilização de controles internos que facilitem a apuração dos custos e a definição de critérios para a sua distribuição aos produtos.

No contexto geral do trabalho, destaca-se que existe a viabilidade de implantação de um sistema de custos em uma secretaria municipal de um município de pequeno porte. A utilização da metodologia do custeio por absorção auxilia os gestores no processo de tomada de decisão, bem como demonstra aos cidadãos a relação entre os custos e os benefícios recebidos pelo município.

Pela importância da gestão de custos identificada no presente trabalho, recomenda-se para futuras pesquisas a aplicação de outras metodologias que sirvam de comparação aos resultados encontrados. Recomenda-se também a aplicação de um sistema de gestão de custos que incorpore todos os setores de um órgão público municipal, ampliando o nível de informação para os gestores municipais. 
Sistemas de custeio na administração pública municipal: uma aplicação da gestão de custos na Secretaria Municipal da Agricultura e Meio Ambiente de São João do Oeste - SC Ari Söthe, Marcelo Silva, Selma Hahn Reichert, Jorge Eduardo Scarpin

\section{REFERÊNCIAS}

BRASIL. Lei Complementar no 101/2000, de 04 de maio de 2000. Estabelece normas de finanças públicas voltadas para a responsabilidade na gestão fiscal e dá outras providências. Disponível em: <http//:www.planalto.gov.br>. Acesso em: 05/jul/2008.

. Lei no 4.320/1964. Estatui Normas Gerais de Direito Financeiro para elaboração e controle dos orçamentos e balanços da União, dos Estados, dos Municípios e do Distrito Federal. Disponível em: <http//:www.planalto.gov.br>. Acesso em: 10/jul/2008.

CARVALHO, João; COSTA, Teresa Carmo; MACEDO, Natália. (2007). A contabilidade analítica ou de custos no sector público administrativo. In: X Congresso Internacional de Custos. Anais...13 a 15 de junho, Lyon, França.

CFC - CONSELHO FEDERAL DE CONTABILIDADE. Resolução CFC $n^{\circ} 1.129$, de 21 de novembro de 2008. Aprova a NBC T 16.2 - Patrimônio e sistemas contábeis. Disponível em: http://www.cfc.org.br/sisweb/sre/detalhes_sre.aspx?Codigo=2008/001129. Acesso em: 05/mai/2009.

. Resolução CFC n 1.133, de 21 de novembro de 2008. Aprova a NBC T 16.6 Demonstrações contábeis.

Disponível

em: http://www.cfc.org.br/sisweb/sre/detalhes_sre.aspx?Codigo=2008/001133. Acesso em: 05/mai/2009.

CRUZ, Flavio da; PLATT NETO, Orion Augusto. (2007). Contabilidade de custos para entidades estatais: metodologia e casos simulados. Belo Horizonte: Fórum.

GARRISON, Ray H; NOREEN, Eric W. (2001). Contabilidade gerencial. (9 ed.). Rio de Janeiro: LTC.

GIL, Antônio Carlos. (1999). Métodos e técnicas de pesquisa social. (5 ed.). São Paulo: Atlas.

HANSEN, Don R.; MOWEN, Maryanne M. (2001). Gestão de Custos. Tradução Robert Brian Taylor. (1 ed.). São Paulo: Pioneira Thomson Learning.

HORNGREN, Charles T.; FOSTER, George; DATAR, Srikant M. (2000). Contabilidade de custos. (9 ed.). Rio de Janeiro: LCT.

IBGE - Instituto Brasileiro de Geografia e Estatística. IBGE Cidades. Disponível em: http://www.ibge.gov.br. Acesso em: 10/jul/2008.

IUDÍCIBUS, Sérgio de. (1998). Contabilidade gerencial. (6 ed.). São Paulo: Atlas. 
Sistemas de custeio na administração pública municipal: uma aplicação da gestão de custos na Secretaria Municipal da Agricultura e Meio Ambiente de São João do Oeste - SC Ari Söthe, Marcelo Silva, Selma Hahn Reichert, Jorge Eduardo Scarpin

MAHER, Michael. (2001). Contabilidade de Custos: criando valor para a administração. Tradução José Evaristo dos Santos. São Paulo: Atlas.

MARTINS, Eliseu. (2003). Contabilidade de custos. (9 ed.). São Paulo: Atlas.

MARTINS, Eliseu. (2000). Contabilidade de custos: inclui ABC. (7 ed.). São Paulo: Atlas.

RAUPP, Fabiano Maury. BEUREN, Ilse Maria. (2004). Caracterização da pesquisa em Contabilidade. In. BEUREN, Ilse Maria (Org). Como elaborar trabalhos monográficos em contabilidade: teoria e prática. (2 ed.). São Paulo: Atlas.

. (2008). Gestão de custos no legislativo municipal por meio do custeio por absorção: um estudo de caso. In: XV Congresso Brasileiro de Custos. Anais...12 a 14 de novembro. Curitiba, PR.

REIS, Luciano Gomes dos; RIBEIRO, Priscila Andreoni Ribeiro; SLOMSKI, Valmor. (2005). Custos no setor público: uma proposta de implementação de sistemas de custeio. In: IX Congresso Internacional de Custos, Anais...28 a 30 de novembro. Florianópolis, SC.

RIBEIRO, Edinéia Nicolau; CAMACHO, Reinaldo Rodrigues. (2006). Custeio ABC aplicado a um centro municipal de educação infantil: um estudo de caso. In: XIII Congresso Brasileiro de Custos. Anais...30 de outubro a 01 de novembro. Belo Horizonte, MG.

SÃO JOÃO DO OESTE. (2000). Lei n.ํ5 539/2000. Lei Orgânica de São João do Oeste/SC. São João do Oeste. Disponível em: http://www2.saojoao.sc.gov.br. Acesso em: 02/fev/2009.

SILVA, Lino Martins da. (2007). Problemas para o Desenho e Implantação de um Sistema de Custos na Administração Pública, o método Activity Based Costing (ABC). In: X Congresso Internacional de Custos. Anais... 13 a 15 de junho. Lyon, França.

SLOMSKI, Valmor. (2001). Mensuração do resultado econômico nas entidades públicas. Chapecó: Argos.

SLOMSKI, Valmor. (2003). Manual de contabilidade pública: um enfoque na contabilidade municipal. (2 ed.). São Paulo: Atlas.

Data de Submissão: 25/03/2010

Data de Aceite: 02/08/2010 